\title{
Feminist and trans perspectives on identity and the UK Gender Recognition Act
}

The British Journal of Politics and International Relations 2016, Vol. 18(3) 67I-687 (C) The Author(s) 2016 Reprints and permissions: sagepub.co.uk/journalsPermissions.nav DOI: $10.1177 / 1369 \mid 48116637998$ bpi.sagepub.com

@SAGE

\author{
Paddy McQueen
}

\begin{abstract}
This article examines Sheila Jeffreys' analysis of the UK's Gender Recognition Act (GRA) and her critique of trans identities. Situating her position within a wider radical feminist perspective, I suggest that her arguments against the GRA are grounded in a problematic understanding of sex and gender. In so doing, I defend how sex and gender are understood in the GRA. Furthermore, I show that radical feminist concerns about sex reassignment surgery and the complicity of trans individuals with stereotypical gender norms are unwarranted. By highlighting the importance of attending to the embodied dimensions of sex and gender, I offer a partial defence of the UK's GRA. In particular, I note the benefits that it can offer to trans individuals, although I suggest ways in which the GRA can be improved. Finally, I challenge radical feminists who see trans theory and identities as inimical to the goals of feminism.
\end{abstract}

\section{Keywords}

feminism, gender, Gender Recognition Act, Sheila Jeffreys, trans identities, transsexuality

\section{Introduction}

Trans theory is emerging rapidly as an influential set of perspectives within gender and feminist studies; it is playing a major role in debates about not only sex/gender ${ }^{1}$ identity but also key socio-political themes including rights, autonomy, power, oppression, inclusion and equality (e.g. Stryker and Aizura, 2013; Stryker and Whittle, 2006). Trans theory is thus contributing significantly to discussions about the central theoretical tenets and political goals of feminism, sometimes challenging long and deeply held beliefs about the purpose of feminist theory and activism (Bettcher, 2014). This has generated a complex, dynamic and occasionally fraught relationship between feminists and trans theorists. ${ }^{2}$ Some thinkers highlight their shared interests and the importance of collaboration (e.g. Butler, 2004; Califia, 1997; Cromwell, 1999; Elliot, 2010; Enke, 2012b; Heyes, 2003; Koyama, 2003; Overall, 2012), while others argue that they are incompatible and that trans theory should have no place within feminism (e.g. Bindel, 2004;

University College Dublin, Ireland

\section{Corresponding author:}

Paddy McQueen, UCD School of Philosophy, Newman Building, University College Dublin, Belfield, Dublin

4, Ireland.

Email: paddymcqueen@gmail.com 
Daly, 1978; Greer, 1999; Hausman, 1995; Jeffreys, 2003, 2005, 2008, 2014a; Raymond, 1994 [1979]). Despite, or because of, these differences, it is clear that trans theory is contributing to the feminist agenda in a multitude of ways and thus feminists must engage - whether positively or negatively — with the issues and arguments being raised within trans studies. Outside of this burgeoning academic field, trans identities are gaining increasing publicity within the media and hence being brought to the greater attention of the general public. ${ }^{3}$ There has also been a proliferation of documentaries, newspaper articles and online blogs about trans identities and issues, in addition to academic articles and books (Stryker, 2013).

It is in the light of these developments that Jeffreys (2008) offers a radical feminist analysis of the UK's Gender Recognition Act (GRA), which grants individuals legal recognition of their desired sex/gender. She argues that the GRA is a problematical piece of legislation that should be retracted because (1) it reinforces stereotypical notions of gender and ultimately hinders the feminist goal of eradicating gender and (2) it is undermined by instances of regret and reversion experienced by trans individuals. She develops these concerns into the wider assertion that trans theory and the existence of trans identities are inimical to the goals of feminism. Jeffreys' claims are echoed by a growing number of feminists who are critical of trans identities, in large part because of the latter's perceived complicity with, even endorsement of, stereotypical conceptions of masculinity and femininity. Consequently, trans identities are accused of being antithetical to the feminist goal of eliminating gender.

In this article, I argue that feminist criticisms of trans identities and the GRA are unconvincing. In response to Jeffreys, I defend how sex and gender are understood within the GRA. I also show that the issues of regret and reversion among trans individuals do not pose a problem for the GRA. I then respond to the more general radical feminist critique of trans individuals, specifically that they are supportive of patriarchy and hence contrary to the goals of feminism. I begin by challenging the radical feminist goal of eradicating gender, arguing instead that we must attend to experiences of embodied gender in order to identify and understand oppression. Such attention highlights the value of the GRA for many trans individuals. I then show that trans individuals are often critical of traditional gender norms and reflective about the problems of patriarchy. Accordingly, contra radical feminist concerns, I suggest that feminism and trans theory can, and should, establish productive collaborations in order to better examine and respond to instances of gender oppression wherever and however they arise. This includes addressing the high levels of violence and oppression experienced by trans individuals, which the GRA can play an important role in combating. Thus, the article addresses both the importance of the GRA itself and the wider, pressing themes of how best to conceptualise gender, role within feminist politics and the relationship between feminism and trans theory.

\section{Trans individuals, feminism and the UK's GRA}

Any discussion of contemporary sex/gender identities is confronted immediately with the issue of definition. The terms 'transsexual' and 'transgender' are contested and multivalent, which makes their use potentially problematic. 'Transgender' is often understood as an umbrella term that refers to people whose sex/gender identities deviate from-and hence challenge - the ways in which sex and gender are conventionally understood within society (National Center for Transgender Equality (NCTE), 2014; Stryker et al., 2008). ${ }^{4}$ The term 'transsexual' is an older one that originated in medical and psychological communities, 
although a number of people continue to define themselves as transsexual. It is often used to denote individuals who identify unambiguously as either male or female and, typically, seek to undergo a permanent change of sex. ${ }^{5}$ I use 'trans' as a general term incorporating the plethora of sex/gender identities, including transsexual identities, which challenge conventional notions embedded in the sex/gender system, while acknowledging that such a definition is contestable and can vary both across and within trans communities. It is not intended to deny or erase the important differences between trans identities. In line with Serano's (2007) recommendation, I use the term 'cis' to refer to individuals whose gender identity conforms to the sex that they were assigned at birth (i.e. people who are non-trans). ${ }^{6}$

Setting definitional caveats aside, the important point for present purposes is that a number of trans individuals experience a sense of gender identity that differs from what is typically associated with the sex they were assigned at birth. This can lead such individuals to choose to transition, a complex process through which they live as the sex/gender that they identify with. Transitioning can involve some or all of the following: changing one's name, dressing and grooming differently, altering one's behaviour, taking hormones, changing official identity documents and/or undergoing surgery. The UK's GRA was introduced in 2004 and grants governmental recognition to trans individuals who want to transition from female to male or vice-versa. While a number of other countries have GRAs, ${ }^{7}$ the UK's legislation is radical insofar as it does not require individuals to have undergone sex reassignment surgery (SRS) in order to be recognised as their desired sex/gender. ${ }^{8}$ Rather, individuals who have not undergone SRS but nevertheless have to alter their sex/gender status must (1) be diagnosed with 'gender dysphoria', ${ }^{9}$ (2) lived as their desired gender for at least 2 years and (3) intend to live with their acquired gender until death (UK Gender Recognition Act, 2004).

The significance of the GRA derives not only from the implications that it has for the lives of trans individuals but also the important, complex ethical and political questions that it raises about sex, gender and identity. The GRA provides a fulcrum for debates about the social accommodation of trans identities, human and legal rights, individual autonomy and social equality. These issues come to a head in arguments over, for example, the use of gendered public toilets and changing rooms by trans people (Jeffreys, 2014b; Molotch and Norén, 2010), trans people's participation in competitive sports (Coggon et al., 2008), the housing of trans individuals in prisons (Mann, 2006; Rosenblum, 2000), marriages involving trans people (Sharpe, 2012) and trans individuals' access to gendered spaces and organisations (Elliot, 2010; Namaste, 2011; Sweeney, 2004). One major reason why these issues are so contentious is because society is deeply structured by a naturalised, binary notion of sex and gender, which is unsettled when individuals cross or blur this binary-something that the GRA makes possible.

Despite the relevance of trans identities and the GRA to many important feminist debates and concerns, Sandland (2005: 44) observes that 'feminists and other critical theorists of gender (and sexuality) have by and large tended to bracket transsexualism off as a minority issue with no particular wider resonances'. Jeffreys attempts to correct this lack of engagement by offering an analysis of the GRA from a radical feminist perspective. It is important to examine Jeffreys' position because she has offered the clearest, most comprehensive and sustained feminist critique of trans identities and politics to date. She thus represents a growing movement against trans identities among radical feminists (Jeffreys, 2014a: 2). Her analysis of the GRA represents a distilled account of her wider theoretical position (Jeffreys, 2003, 2005, 2014a) and thus provides a useful means to 
assess her overall arguments - and radical feminist arguments more generally — about trans identities.

Jeffreys' overarching contention is that 'the GRA is a retrogressive legislation which inscribes traditional gender roles into law so that they can be identified and regulated by the state' (Jeffreys, 2008: 331). Consequently, the GRA should be removed from UK law as it hinders efforts to eradicate the oppression of women. Jeffreys' stance is underpinned by her belief that gender is an essentially patriarchal concept that embodies 'forms of behaviour which stem from and maintain unequal power relations between the sexes', and thus needs to be 'eliminated' (Jeffreys, 2008: 331). She concludes that trans identities are problematic because they are dependent upon, and constructed by, gender. This echoes arguments that Jeffreys $(2003,2005)$ has offered previously and connects with concerns raised by other radical feminists who criticise trans identities for embodying conservative and patriarchal conceptions of masculinity and femininity (e.g. Bindel, 2004; Burchill, 2001; Daly, 1978; Hausman, 1995; Raymond, 1994 [1979]). There are, then, two distinct but related arguments offered by Jeffreys. Her first concerns the legislation of the GRA itself; her second addresses trans identities and their status within feminist politics. I will deal with each in turn before considering the future of the GRA and the relationship between feminism and trans theory.

\section{Jeffreys' analysis of the GRA}

Jeffreys' major complaints against the GRA centre upon the way in which sex and gender were understood within government debates about the GRA Bill and the implications this has for issues of reversion and regret with regard to trans individuals (Jeffreys, 2008: 332-336). She argues that the legislation 'is mired in a profound confusion over the difference between sex and gender' (Jeffreys, 2008: 333). Specifically, the GRA does not distinguish adequately between sex and gender as two distinct phenomena. She quotes the following statement made by Lord Filkin, a major proponent of the GRA during its drafting, as being particularly problematic:

The Bill is about legal recognition and it will define a person's sex in law. We consider the arguments about the meaning of the words 'sex' and 'gender' to be beside the point. There is no stark dichotomy between the meaning of the words. (quoted in Jeffreys, 2008: 334)

Jeffreys objects to this position, referring to it as 'casuistry' (Jeffreys, 2008: 334). She insists that sex and gender should be kept distinct, with the former being grounded in biological facts about a person (Jeffreys, 2014a: 5). Jeffreys is thus critical of Lord Filkin's claim that the "word "sex" now has more of a social and psychological connotation than it would have had 20 or 30 or so years ago' (quoted in Jeffreys, 2008: 334).

However, there are good reasons to endorse Lord Filkin's refusal to distinguish sharply between sex and gender, as well as his claim that sex has a social dimension. A number of theorists have offered persuasive arguments against the idea that sex can be easily defined in terms of biological facts about the body without reference to cultural factors, thus undermining the idea that they are distinct (Fausto-Sterling, 2000; Gatens, 1996; Grosz, 1994). For example, Fausto-Sterling $(1993,2005)$ demonstrates that cultural conditioning shapes many sex-specific traits assumed to be purely natural. Her work reveals how social practices shape biology so that we cannot speak of a natural body as it is in itself. Similarly, Fujimura's research into genetic sex determination collapses the sex-gender distinction 
by showing that 'Sex, even at the genetic level, is a sociomaterial process and product' (Fujimura 2006, 75) and hence the categories 'male' and 'female' are 'already and always social categories' (Fujimura 2006, 76). This reflects the experiences of many trans individuals, for whom identity and the body intertwine in ways that undermine the distinction between physical sex and social gender (Schrock et al., 2005).

Furthermore, what constitutes or counts as the essential aspect(s) of a person's sex is also the product of social discourses and practices (Overall, 2012: 254). This can be seen from both the historically and culturally variable ideas about what determines a person's sex and also the ambiguity over what, specifically, makes someone a male or a female. Are external genitalia, internal reproductive organs, chromosomes, hormones, internal reproductive organs, or some combination of all of these, to be taken as the ultimate signifier(s) of sex? It is noteworthy that such concerns were expressed by Professor Robert Winston during the House of Lords second sitting of the GRA Bill. He stated that:

The definition of sex is extremely complicated ... to define it simply as genital, hormonal or, as the noble Lord, Lord Tebbit [an opponent of the Bill], seeks to do, as gonadal, is a travesty of what really happens ... I urge the House to be very cautious about defining it in terms of chromosomal, genital or any other simple definition. It simply is not medically just, and I am sure that it would produce bad law. (Gender Recognition Bill, House of Lords Report Stage, Hansard 03/02/2004, cols. 619-620)

Jeffreys also objects that the GRA is flawed because it uses the concept of gender to guide the legal alteration of a person's sex. Thus, it allows a person's acquired gender to determine what their sex will be, and so someone born with a body that is sexed as female can still legally become male, even if their body is not physically altered. This means that the very notion of 'sex' is in danger of being disconnected from biology because there will be people legally classified as 'male' who do not have a penis, testicles or other signifiers of the male sex. As Lord Tebbit argued in opposition to the Bill:

Sex cannot be changed ... Sex is decided by the chromosomes of a human being ... there is no law nor any medical procedure that can change the sex of a human being. The Bill purports to do so. It is therefore an objectionable farce. (Gender Recognition Bill, House of Lords Second Reading, 18/12/03, Hansard: Column 1304)

Jeffreys (2008: 334) commends him for his stance. She refuses to use the terms MtF (male-to-female) and FtM (female-to-male) because 'they give the mistaken impression that sex can be changed when, in fact, it cannot' (Jeffreys, 2014a: 8).

The belief that one's sex at birth is determined by nature and fixed for life is a common one among critics of trans identities and the GRA (e.g. Bindel, 2004; Burchill, 2001; Greer, 1999; Raymond, 1994 [1979]). As Bindel (2009) argues, 'a trans-sexual "woman" will always be a biological male'. However, such a position has received substantial criticism from feminists and trans theorists (see Elliot, 2010: 113-148; Shrage, 2009). One problem is that we need to justify why the sex that one is assigned at birth should be the final determinant of one's adult identity, especially when we acknowledge that many other aspects of our identity change over time. It merely begs the question to hold that only individuals born male or female can truly be men or women because what makes us men or women is our sex at birth. As Enke (2012a: 1) notes, rather than being natural and present from birth 'Gender, and also sex, are made through complex social and technical manipulations'. Accordingly, Overall (2009) has 
argued that sex/gender transitioning should be placed alongside other personal transformations through which we shape our identities.

One response is to say that it is one's experiences as being male or female that determines one's sex/gender category, and transsexuals have not experienced being their desired sex/gender. However, it is not clear what experiences will count as being the true experiences of being a man - and invariably whatever experiences we choose will not be had by some people born and recognised as male. Aside from this problem of essentialising identity, there are many trans individuals who do live as their desired sex/gender prior to hormonal or surgical transitioning, which would provide them with the relevant experience (perhaps so long as they successfully pass). It again seems arbitrary to say that only those born as male or female can have the requisite experiences of being male or female, or that such experiences can only be had by people with certain biological features present from birth. In addition, many trans individuals really do feel that they are male or female, despite the physical bodies that they were born with, and it is hard to see why and how we can or should disregard this phenomenological evidence in favour of an unsubstantiated assertion that the body one is born with is/should be the final determinant of one's later identity (Rubin, 2003). In the light of these issues, there seems good reason to endorse the GRA's move away from the beliefs that one's sex is fixed at birth and that there is a neat dividing line between one's biological sex and social gender. As Overall observes, individuals who transition show that:

belonging to a sex is a social, not a biological, phenomenon; that one's sex is not inevitably fixed and immutable; and that one's genitalia (or any other body characteristics) do not inevitably represent, let alone determine through biological inevitability, who or what one is. (Overall, 2012: 255)

Jeffreys' attempt to sharply separate biologically given sex from culturally constructed gender leads her to conceive of a person's desire to change their legal sex/gender as behaviour that is subject to choice and simply an alteration in lifestyle. She argues that the GRA misunderstands gender because it requires the applicant to stay in their chosen gender for life, which gives it an 'essential' quality and sets 'in aspic the change that it recognises' (Jeffreys, 2008: 335). Her concern is that 'Behaviours which are subject to choice and not biology cannot be dictated in this way' (Jeffreys, 2008: 335). There is good reason to agree with Jeffreys' complaint about the GRA's stipulation of permanency because it implies a picture of the self as fixed and stable. This overlooks the self's more fluid and unpredictable nature (McQueen, 2015b). However, Jeffreys' attempt to reduce gender to a 'lifestyle choice' is problematic because it misrepresents the embodied realities of trans individuals. What is striking about many trans self-narratives - and, indeed, the selfexperiences of cis individuals too - is that their sense and experiences of gender are precisely not a matter of choice but rather something that they experience as an ingrained, immutable and essential aspect of their self (e.g. Davy, 2011; Hines, 2007; MasonSchrock, 1996; Rubin, 2003). Crucially, Jeffreys does not distinguish between genders as it is socially recognised and gender as it is lived at the level of embodied existence. While the former is subject to some degree of choice on the agent, the latter is not. The GRA provides individuals with the choice of how their sex/gender is recognised, given their sense of sex/gender identity. The GRA thus aims at responding to a pressing problemthat of gender dysphoria and the difficulties that trans individuals experience-rather 
than resolving seemingly intractable debates about the causes of gender dysphoria or what really makes someone a man, woman or both/neither.

Jeffreys' final argument against the GRA follows on from her discussion of gender as a lifestyle choice. She claims that the GRA is undermined by individuals who transition but later regret their decision and/or revert to their previous sex/gender. Such individuals pose problems for the GRA's requirement that applicants intend to spend the rest of their life in their chosen sex/gender. More fundamentally, Jeffreys (2008, 2014a) argues that experiences of regret and reversion undercut both the diagnosis of gender dysphoria and the very process of transitioning itself. She approvingly quotes an opponent of the Bill, Baroness O'Cathain, who highlighted the case of Alan Finch as an example of the problems of diagnosing gender dysphoria and offering SRS (Jeffreys, 2008: 335). Alan Finch is an Australian MtF transsexual who underwent SRS but later returned to living as male. He then set up a website and pressure group, which campaigned against SRS and hormone treatment. ${ }^{10}$ Finch represents a growing movement against the use of SRS and other processes that enable gender transitions. ${ }^{11}$ Jeffreys rejects a trans individual's right to undergo state-supported surgery, arguing that there 'is nothing flexible about carving "gender" on to the body with surgery and hormone treatments, as those who regret their “choices" discover' (Jeffreys, 2008: 341). More recently, she has referred to SRS as a 'mutilating practice' (Jeffreys, 2014a: 70). ${ }^{12}$

One can certainly agree with Jeffreys that we should strive to avoid cases of posttransition regret. ${ }^{13}$ Indeed, there is much research by clinicians into how levels of regret and reversion with regard to SRS can be minimised and ideally eliminated (e.g. Landén et al., 1998; Lawrence, 2003; Olsson and Möller, 2006; Smith et al., 2001, 2005). ${ }^{14}$ However, the available empirical evidence shows that instances of regret and reversion among individuals who undergo SRS are extremely low (Pearce, 2014). In one study involving 232 participants, no one reported consistent regret following SRS, and 15 participants (6\%) were sometimes regretful (Lawrence, 2003). Only 2 participants (1\%) had reverted to their prior sex/gender. More than $96 \%$ of participants gave a positive rating to their overall happiness with SRS, and 97\% reported that SRS had improved their quality of life. Similarly, Landén et al. (1998) found that 8 out of 213 participants $(3.8 \%)$ in their study applied for reversal following SRS. Finally, Smith et al. (2005) report that out of 162 participants $98.4 \%$ expressed no regrets about SRS, $91.6 \%$ were satisfied or very satisfied with the results of SRS and $8.4 \%$ were neutral. Such research leads Whittle and Turner (2007: 3.15) to conclude that there is 'strong evidence that the quality of life and mental health is much improved for a significant majority of trans people [after] reassignment'.

On the issue of regret and reversion, Jeffreys is right to challenge the GRA's stipulation of permanency; it should be possible for those who apply to the GRA to later change their sex/gender identity. We should also be concerned about those who experience regret or negative results from SRS, no matter how small the numbers. However, this does not mean that we should eradiate the GRA and ban SRS. To do so would be to deny people options that often have a positive impact on their lives. As one individual said of the GRA, 'I do think it's improved the quality of my life to a level that I could never have thought possible' (quoted in Hines, 2013: 23). The availability of SRS and the GRA is particularly important given the severe social difficulties encountered by trans individuals, as both options can make a significant contribution to trans individuals' well-being. Furthermore, if one only discusses instances of regret and reversion, as Jeffreys does, then one is in danger of offering an unrepresentative and one-sided account of trans 
experiences. This prevents an accurate and productive discussion of the relative merits or demerits of the GRA and SRS. In the light of this, Pearce (2014) has warned of the harmful effects that discussions of trans regret, especially as this is portrayed in the media, can have on trans individuals.

Finally, occurrences of regret do not mean that we should prevent people from transitioning. It might well be a condition of respecting people's autonomy-including their capacity to determine what happens to their bodies - that we allow them to undertake actions that they may later regret, especially if they do not expect that they will regret them. At the very least, we would need to provide arguments, which anti-SRS campaigners are yet to provide, as to why we can override someone's autonomy in order to prevent them transitioning via the GRA or SRS. This is especially the case if we think that individuals have a prima facie right to bodily self-determination (Currah et al., 2006; Feinberg, 1998), something that many feminists have long asserted.

\section{Trans identities, gender and patriarchy}

The criticisms that Jeffreys aims at the GRA fail to hit their mark; she provides no good reason to see it as inherently flawed. However, Jeffreys also claims that the GRA and trans identities are inimical to the goals and central tenets of feminism. This is because trans identities are dependent upon the concept of gender for their legibility, and radical feminist politics is aimed precisely at the elimination of gender itself. She thus draws a sharp line between, on the one hand, trans, queer and post-structural feminism, and, on the other hand, radical feminism:

[W] here a radical feminist approach to transgenderism parts company with the post-modern/ queer analysis is in seeing the problem with gender residing not just in the fact that gender is too rigidly policed and should be more flexible, or even played with, but in the concept of gender itself. Radical feminist theory rejects the notion of transgenderism since it requires the acceptance of 'gender' as a useful category. If the notion of 'gender' is rejected then transgenderism does not make sense. (Jeffreys, 2008: 338)

The difference between these approaches hinges in large part on how 'gender' is understood within them. Radical feminists tend to define gender as 'a social hierarchy (masculine and feminine), ringed with stereotype, enforced by socialization [as well as physical force] to subordinate' (MacKinnon, quoted in Jeffreys, 2008: 339). On this view 'masculinity is the behaviour and status of the ruling class of men and femininity is the status of the subordinate class of women. It would not make sense, therefore, to preserve [gender]' (Jeffreys, 2008: 339-340). This brings to light the essential problem with the GRA for Jeffreys: once we see the task of feminism as eliminating gender, then the GRA - insofar as it is based upon, and thus sustains, the concept of gender as meaningful and valuable - is rendered as unconducive to this goal.

How one should understand gender is a contentious, on-going debate within feminism, which cannot be answered decisively here. However, it is possible to challenge Jeffreys' definition of gender as pertaining solely to patriarchal behaviours and social roles for being overly limited and reductive and for producing a problematic politic. Specifically, Jeffreys ignores the complex and varied ways in which individuals reflectively and critically take up gender as a set of embodied experiences, values and dispositions. From the perspective of embodied reality, gender appears as a set of sexual, psychological, physical and social dimensions of selfhood that help to structure our ability to make sense of and 
affirm ourselves. Eradicating gender — if such a thing were possible — would thus remove a central crux through which we construct a relation-to-self.

This observation challenges Jeffreys' (2008: 338) claim that gender is not a useful category. It is hard to discern how and why we should eradicate gender from our lives when it is so deeply embedded in our individual and collective sense of selves. Indeed, Mikkola (2011) has argued that positions such as Jeffreys are normatively unappealing for two reasons. First, because many people do not distinguish between sex and gender in their everyday experience and hence will find it difficult to understand or relate to a politic that seeks to eliminate one but not the other; second, we often experience our gender as a positive source of value and will thus be resistant to removing something that enhances our sense of self. Furthermore, focusing on gender as a social structure can overlook aspects of oppression and inequality that are only revealed by an analysis of embodied subjectivity (McNay, 2014). Part of the promise of trans theory is its ability to reveal power dynamics embedded in gender discourses and practices through its attention to the embodied experiences of trans individuals.

As noted above, there are good reasons to challenge the assertion that 'sex' and 'gender' can and should be sharply distinguished, which is a foundational aspect of Jeffreys' radical feminist politics. Moi (1999: 4-5) argues that the movement to eliminate gender produces an impoverished theory of subjectivity because it fails to offer 'a concrete, historical understanding of what it means to be women (or a man) in a given society'; it overlooks the embodied aspects of existence wherein one's sex and gender are experienced as inseparable aspects of embodied selfhood. This is reflected in the self-narratives of many trans individuals (e.g Nagoshi et al., 2012; Rubin, 2003; Schrock et al., 2005), for whom the self could not be understood without the notion of embodied gender. Once we see sex and gender as inextricably intertwined, it is hard to make sense of a feminist politics that seeks to eradicate one while retaining the other.

Jeffreys' position leads her to claim that we should 'reject' trans identities, meaning that she denies the viability and/or acceptability of trans identities. This fits with the position of Janice Raymond, cited by Jeffreys (2014a: xiii) as a major influence on her work, who argues that 'the problem of transsexualism would best be served by morally mandating it out of existence' (Raymond, 1994 [1979]: 178). Radical feminist scepticism of trans identities springs from the belief that gender is simply an expression of patriarchal values about masculinity and femininity. Trans identities, which rely on gender in order to be meaningful, are therefore reliant upon and reproduce patriarchy. They are deemed to be essentially conservative and problematic insofar as they maintain and reproduce stereotypical, patriarchal conceptions of femininity and masculinity (Bindel, 2004; Jeffreys, 2005; Raymond, 1994 [1979]). Burchill (2001) describes transsexuals as follows: 'they are woefully conventional souls ... It is the literal-mindedness, the clunky logic of transsexuals that is so appalling (that, and their taste in blouses) ... They are frilly, docile smilers who always wear make-up and never the trousers'. From this radical feminist perspective, the GRA is problematic because it supports the existence of trans identities by granting them legal recognition, which in turn reinforces patriarchy and the oppression of ('real') women.

Attention to the beliefs of trans individuals belies the radical feminist assertion that they are necessarily supportive of conservative, patriarchal gender norms. Trans individuals often reflect critically on the problems with gender norms and the ways that they can reinforce conventional conceptions of men and women (e.g. Cromwell, 1999; Davy, 2011; Hines, 2007; Monro, 2005; Namaste, 2011). As Rubin (2003: 2) notes, 'One of the 
biggest misunderstandings of FTM transsexual lives is that they conform to traditional notions of gender'. The assertion that transsexuals uncritically endorse patriarchal stereotypes of gender is unjustified and promulgates an unhelpful distortion of trans identities. It is important to counter this claim because it has gained traction through being voiced by a number of trans critics (Bindel, 2004; Hausman, 1995; Jeffreys, 2003; Raymond, 1994 [1979]). Burchill (2001) writes of transsexuals as follows: their 'idea of womanhood seems to have survived intact from 1953. Despite their sticky lipstick rictuses, they are the ultimate example of a particularly middle-class, middle-aged male arrogance' (which also implies that all transsexuals are MtF). In addition to lacking empirical support, this criticism strips trans individuals of critical self-reflection and agency (Davy, 2011; Heyes, 2003). It substitutes the real-life experiences and beliefs of trans individuals, especially their complexity and diversity, for homogeneous, stereotyped and ungrounded representations.

Furthermore, not all medical practitioners are either consciously or unconsciously acting as a conduit for patriarchal values. Many distance themselves from such values and some utilise feminist frameworks to help them work with trans individuals (e.g. May, 2002). The medical community is not the monolithic expression of patriarchal domination that Jeffreys - and other critics of trans identities, such as Hausman (1995) and Raymond (1994 [1979]) — assert that it is. In terms of the GRA, Jeffreys (2008: 332) argues that it reinforces problematic gender stereotypes because members of the GRA panel are likely to invoke their assumptions about what men and women should be like. There is certainly reason to be concerned if the diagnosis of gender dysphoria and the GRA panel are guided by conventional conceptions of 'proper' masculine and feminine identities, which can cause some individuals to be denied recognition because they fail to meet these normative expectations. However, Whittle and Turner (2007: 6.11) report that, as of January 2007, 1704 people had been awarded a gender recognition certificate whereas only 40 applications had been rejected, and most of these were of ex-patriots who were unable to provide the requisite medical evidence.

This suggests that the GRA panel is not applying a narrowly stereotypical conception of what a man or a woman is like. ${ }^{15}$ It should also be noted that Stephen Whittle, a leading trans activist and gender theorist, was invited to sit in on sessions of the GRA panel in order to assess them. While the medical community has historically enforced a heavily normalised conception of masculine and feminine identity, the situation is changing as practitioners become more aware of trans issues. Problems certainly do persist with how trans individuals are understood and treated by practitioners (Whittle et al., 2007, 2008), and a number of trans individuals report negative experiences with the medical community (Davy, 2011; Hines, 2013). However, this suggests the need for better education on trans issues within the medical community rather than abolishing the GRA and preventing individuals from transitioning.

\section{Feminism and the future of the GRA}

In the two previous sections, I responded to Jeffreys' critique-and the radical feminist perspective more broadly - of both the GRA and trans identities. I defended the way in which sex and gender are conceptualised within the GRA, countered concerns about the occurrence of regret and argued that neither the GRA nor trans identities are inherently supportive of patriarchy. This should allay the fears that some feminists harbour about trans identities and provide a counterbalance to unwarranted stereotypes of trans 
individuals. It also challenges Jeffreys' (2008: 342) conclusion that the GRA 'inscribes patriarchal notions of correct gender roles into law and regulations by the state'. Consequently, I suggest that feminists have little reason to see trans theory and trans individuals as a threat to their political aspirations. Indeed, there are growing transfeminist movements that seek to build coalitions between trans and cis theorists and activists while sharing the radical feminist aims of combating patriarchy and liberating women (e.g. Enke, 2012b; Koyama, 2003). As Elliot (2010: 28) notes, 'many trans people identify with feminism or seek allies in the feminist community'.

Nevertheless, this may not satisfy feminists committed to the belief that only biological women can ever be considered women. This position incorporates feminists who do not explicitly criticise trans identities such as Braidotti (1994: 187) and Grosz (1994: 207), who suggest that 'Men, contrary to the fantasy of the transsexual, can never, even with surgical intervention, feel or experience what it is like to be, to live, as women'. Within this ontological perspective, Heyes (2003: 1108) has suggested that the 'hypothesis that transgender is antifeminist seems unfalsifiable, and one is left wondering if there could be any kind of trans life that would satisfy Raymond [and other radical feminists] with its feminist credentials and contribution to social transformation' (cf. Riddell, 2006: 150). If we cannot overcome this theoretical stand-off, then we can at least tackle trans critics on important matters of detail. Thus, I have shown that many of the assertions that radical feminists make about trans individuals are unsubstantiated. Furthermore, I have argued that a feminist politics that seeks to eradicate gender overlooks the ways in which it is lived at the level of embodiment. This leads radical feminist critics of trans identities to disregard the frequent distress that accompanies gender dysphoria and hence to ignore a major reason why the GRA is to be welcomed.

The inattention to the difficulties encountered by trans individuals demonstrated on the part of Jeffreys and other radical feminists may represent an example of what Serano (2007) labels 'cissexualism'. This term denotes the privileging of individuals whose biological sex and sense of gender identity align. Insofar as cis identities are taken as normative, trans identities can only appear as deviant and abnormal, which both compounds and legitimates the social difficulties that they encounter. This is reflected in the fact that cis individuals are rarely required to prove or justify their identity, while trans individuals are continually subject to authenticating practices. ${ }^{16}$ Countering cissexualism involves selfreflection on one's own positioning within a socially constructed, exclusionary sex/gender system as well as attending to the issues encountered by people who fall outside of the normative boundaries of sex/gender identity. ${ }^{17}$

Trans individuals frequently encounter social stigma, exclusion and both verbal and physical violence owing to their identities (Gordon and Meyer, 2008; Lombardi et al., 2001; Stotzer, 2009; Whittle et al., 2007). In one study (Whittle et al., 2007), 73\% of respondents experienced harassment, $47 \%$ did not use public or leisure facilities for fear of discriminatory treatment and $45 \%$ experienced family breakdowns. The researchers conclude that trans people 'experience high levels of inequalities and discrimination in all walks and aspects of life' (Whittle et al., 2007: 9). This often has a severe negative impact upon the lives of trans individuals, as evidenced by the prevalence of suicide attempts by members of the trans population (Haas et al., 2011; Moody and Smith, 2013), with studies reporting a figure of $41 \%$ (Haas et al., 2014), 29.9\% (Whittle et al., 2008) and $34.4 \%$ (Whittle et al., 2007). This compares, for example, to the $0.6 \%$ of the non-trans population in the United States that has attempted suicide. ${ }^{18}$ The National Health Service (NHS, 2012) meanwhile states that there are at least 140,000 suicide attempts in England and 
Wales each year, which represents just $0.24 \%$ of the population. ${ }^{19}$ Liu and Mustanksi (2012) have reported on the high levels of suicidal ideation and self-harm among trans youth, while Whittle et al. (2007) note that trans individuals are overrepresented in the prison population.

Given these figures, legislation that helps to validate the identities and experiences of trans individuals by recognising the legitimacy of their claims is valuable, even if it is not perfect. As one transsexual stated:

Transsexuals have gone from being socially unacceptable to being sanctioned by government. And that makes a big difference for many people. Whereas they thought that I was some sort of crazy, now Parliament is saying I'm perfectly all right, and there are many other people like me, and that's a good thing. (quoted in Hines, 2013: 22-23)

This quote highlights the symbolic value of the GRA; in addition to the practical benefits it offers, it can help to further the social acceptance of trans identities by recognising the legitimacy of their claims and experiences. Hines (2013: 66) observes that 'Research findings indicate that the GRA has had positive impacts for many participants in terms of the practical benefits it has brought ... For some participants, the GRA also brought increased esteem through the legitimation of their identity'.

This does not mean that the GRA is without problems and there is certainly room for improvement moving forward. In particular, Hines (2007), Davy (2011) and Sandland (2005) highlight the fact that the GRA remains wedded to a binary notion of gender, which can work to exclude some trans identities - for example, intersex, bi-gendered and androgynous identities - from legal recognition on the grounds that the GRA only accommodates individuals who identify as unambiguously 'male' or 'female'. We should thus consider ways in which the GRA, and society in general, can better respond to and accommodate the plethora of transgender identities that sit outside the gender binary (Hines, 2013; Monro, 2005). Furthermore, the stipulation that one intends to spend the rest of one's life in one's chosen sex/gender category appears problematic when placed alongside a model of the self as fluid because the GRA implies stability and predictability of the self that often eludes us. Thus, it would be appropriate to remove this requirement of the GRA.

Finally, a number of trans theorists, activists and individuals have argued against the GRA's reliance upon medical practitioners, who are necessary for the diagnosis of gender dysphoria (see, for example, Davy, 2011; Hines, 2013). On this last point, it is instructive to consider the recent GRA passed in Denmark, which only requires that (1) individuals affirm their desire to change sex/gender and (2) reaffirm this desire six months later. Providing that these two conditions are met, individuals will be able to change their legal sex/gender status. This marks a complete break from the medicalised dimension of trans identities by removing the requirement that the applicant be diagnosed with gender dysphoria. However, one reason that the complete de-medicalisation of trans identities is controversial is that state funding for hormone treatment, SRS and other medical practices (e.g. counselling) will be harder to obtain if they are not seen as medically necessitated, which is something that the diagnosis of gender dysphoria secures.

What is clear is that debates about the GRA, and trans identities in general, are complex and far from settled. They continue to be of relevance as governments introduce GRAs, as the Republic of Ireland is doing this year, and as trans theory challenges and enriches feminist theory and practice. As noted at the outset, the GRA also raises important ethical and 
political questions, such as the use of public gendered spaces by trans individuals. This is because the GRA challenges the established notion that biological sex supervenes onto social gender, such that only those born, say, female, can ever be properly considered female. There is important work to be done in thinking through the increasing ways in which settled concepts of sex and gender are being shaken by trans identities, which requires that feminists of every ilk engage with trans theory and activism.

However, that the GRA gives rise to complex, contentious issues is not reason to reject it. Rather, we should seek to foster constructive dialogue within and across trans and cis communities, as well as within the academic community, in order to understand and accommodate individuals who feel an often irresistible need to change their sex/gender. To reject trans identities, as many radical feminists do, is to disregard the social suffering of a number of individuals and also to foreclose the possibility for exploring new ways of inhabiting sex/gender identities. This suggests the necessity of a feminism that can embrace a plurality of sex/gender identities and practices, with a focus on working through rather than ostracising difference. Within such a (trans)feminist perspective the GRA forms part of a wider movement to accept, rather than eradicate, diversity and to respect the embodied realities of all individuals, trans or otherwise.

\section{Conclusion}

The relationship between radical feminists and trans individuals is an often fraught one. Radical feminists accuse trans individuals of reinforcing gender stereotypes and hindering efforts to eradicate gender, going so far as to argue that trans identities do not make sense and should be eliminated. The GRA is criticised for supporting trans identities and reinforcing gender, which contributes to the continued oppression of women. In this article, I have sought to alleviate the concerns of radical feminists by responding to criticisms of both the GRA and trans identities. Focusing on Jeffreys' work as representative of this critique, I have argued that her concerns about the way in which sex and gender are understood within the GRA, as well as her worries about transsexual regret and reversion, are unfounded. Furthermore, I demonstrated that the GRA does not necessarily reinforce patriarchal stereotypes of men and women. Consequently, I challenged Jeffreys' assertion that it is a regressive piece of legislation. Instead, I revealed the important practical and symbolic benefits it can bring to the lives of some trans individuals.

Having defended the GRA against Jeffreys' critique, I then turned to the wider radical feminist rejection of trans identities. Challenging the radical feminist goal of eliminating gender, I argued that gender is an important component within an effective feminist politics and that the aim of eradicating gender is both conceptually problematic and normatively unappealing. In particular, I stressed the importance of attending to experiences of gender embodiment as both a source of positive self-understanding and as a means to identify and respond to instances of oppression. I then turned to the claim that trans individuals are 'dupes' of a patriarchal gender system, which is a criticism frequently voiced by radical feminists. Attending to the beliefs and experiences of trans individuals belies this concern, for they are often highly critical of gender norms and the medical system that enforces them.

On the basis of this analysis, I concluded that there is little reason to see the goals and concerns of feminism and trans theory as necessarily incompatible. Indeed, as noted, there is a growing transfeminist movement that seeks productive collaboration and shared understanding between trans theorists and feminists of every ilk. One major task for an 
effective transfeminism is to explore how best to accommodate the plethora of sex/gender identities that currently exist within society and to respond to the pervasive violence and exclusion that many trans individuals experience. Part of this task will involve informed, productive discussion of the GRA, an acknowledgement of its merits and an analysis of how it might be improved. It is hoped that this article has made a valuable contribution to such a discussion as well as attempts to generate an inclusive, transfeminist movement.

\section{Acknowledgements}

Paddy McQueen is extremely grateful to the British Journal of Politics and International Relations' (BJPIR's) anonymous reviewers for their insightful and extensive comments on the paper.

\section{Funding}

Paddy McQueen is funded by an Irish Research Council Government of Ireland Postdoctoral Fellowship.

\section{Notes}

1. I write 'sex/gender' because, as argued in this article, I do not think an easy demarcation can be made between the two terms. Thus, 'sex/gender' denotes the complex interplay between one's physical body and the cultural signification of bodies and behaviours without implying that 'sex' is a purely biological phenomenon and 'gender' a purely social one.

2. This is not to imply that 'trans theory' and 'feminism' represent two unified, homogeneous camps. There are important internal disagreements and tensions within both traditions (see Elliot, 2010).

3. One poll conducted in America in 2011 found that two-thirds of participants reported being well informed about transgender people and issues. Available online at: http://publicreligion.org/research/2011/11/american-attitudes-towards-transgender-people/\#.VfqPn5coef4

4. Thus, 'transgender' as a general term can include inter alia, transsexual, gender queer, bi-gender, gender fluid, polygender, androgyne, gender neutral queer, intersex, drag and transvestite identities (see Monro, 2005: 194-196 for a glossary of these terms).

5. Some transsexuals will also identify as transgender while others will not. Similarly, some transgenderidentified individuals may also be happy to identify as transsexual while others will not.

6. The term 'cis' helps to highlight and question the assumption that being non-trans represents the default and normative position; it gives a name to something that is otherwise taken for granted and hence not considered necessary to name. In so doing, it challenges the tendency to only name that which is different and/or deviant.

7. A comprehensive list of countries' gender recognition systems is provided by the UK justice system: http://www.justice.gov.uk/downloads/tribunals/gender-recognition-panel/list-of-approved-countries-orterritories/table-approved-countries.pdf

8. In 2014, Denmark passed an even more radical Gender Recognition Act (GRA), which only required that individuals affirm their desire to change gender and then reaffirm this desire six months later. Thus, the trans individual is not required to produce any psychiatric and/or medical documentation in support of their application. I discuss the Danish GRA in the final section of the article.

9. 'Gender dysphoria' is a clinical term that denotes a condition wherein a person experiences discomfort or distress owing to a mismatch between their biological (assigned) sex and their sense of gender identity.

10. The website has since been archived (http://rove.nla.gov.au/work/35124984?q=+\&versionId=43621738).

11. See the website Sex Change Regret (http://www.sexchangeregret.com), Bindel (2009) and Jeffreys (2014a).

12. If Jeffreys' argument that occurrences of regret and reversion undermine the justification for sex reassignment surgery (SRS) is persuasive, then it could well be read as supporting rather than challenging the GRA. This is because the GRA does not require that applicants undergo SRS, which means that it sidesteps any potential problems associated with SRS.

13. However, owing to the nature of identity, it might not be possible to prevent all cases of regret. Furthermore, experiences of regret need not be seen as necessarily problematic.

14. We should, however, be cautious about how the concept of 'regret' is understood within such studies (McQueen, 2015a).

15. Unless the only applicants are individuals who exhibit thoroughly conventional sex/gender identities, which is possible, although unlikely, given the diversity of the trans population. 
16. For an extensive list of examples of cis-privilege, see http://itspronouncedmetrosexual.com/2011/11/ list-of-cisgender-privileges/

17. See St James (2015) for a good response to the controversies that the ideas of cissexualism and cisprivilege have generated.

18. http://www.cdc.gov/violenceprevention/pdf/suicide-datasheet-a.pdf

19. This figure appears to be based on the assumption that each suicide attempt is by a different person, which may be unjustified.

\section{References}

Bettcher M (2014) Feminist Perspectives on Trans Issues. Stanford Encyclopedia of Philosophy. Available at: http://plato.stanford.edu/entries/feminism-trans/ (accessed 12 May 2016).

Bindel J (2004) Gender benders, beware. The Guardian, 31 January. Available at: http://www.theguardian.com/ world/2004/jan/31/gender.weekend7 (accessed 30 March 2016).

Bindel J (2009) The operation that can ruin your life. Standpoint, November. Available at: http://standpointmag. co.uk/the-operation-that-can-ruin-your-life-features-november-09-julie-bindel-transsexuals (accessed 30 March 2016).

Braidotti R (1994) Nomadic Subjects: Embodiment and Sexual Difference in Contemporary Feminist Theory. New York: Colombia University Press.

Burchill J (2001) Gender bending. The Guardian, 20 January. Available at: http://www.theguardian.com/lifeandstyle/2001/jan/20/weekend.julieburchill (accessed 30 March 2016).

Butler J (2004) Undoing Gender. London: Routledge.

Califia P (1997) Sex Changes: The Politics of Transgenderism. New York: Cleis Press.

Coggon J, Hammond N and Holm S (2008) Transseuxals in sport-Fairness and freedom, regulation and law. Sport, Ethics and Philosophy 2(1): 4-17.

Cromwell J (1999) Transmen and FTMs: Identities, Bodies, Genders, and Sexualities. Champaign, IL: University of Illinois Press.

Currah P, Juang RM and Minter SP (eds) (2006) Transgender Rights. Minneapolis, MN: University of Minnesota Press.

Daly M (1978) Gyn/Ecology: The Metaethics of Radical Feminism. London: Women's Press.

Davy Z (2011) Recognizing Transsexuals: Personal, Political and Medicolegal Embodiment. Farnham: Ashgate.

Elliot P (2010) Debates in Transgender, Queer and Feminist Theory: Contested Sites. Farnham: Ashgate.

Enke A (2012a) Introduction: Transfeminist perspectives. In: Enke A (ed.) Transfeminist Perspectives in and beyond Transgender and Gender Studies. Philadelphia, PA: Temple University Press.

Enke A (ed.) (2012b) Transfeminist Perspectives in and beyond Transgender and Gender Studies. Philadelphia, PA: Temple University Press.

Fausto-Sterling A (1993) Myths of Gender: Biological Theories about Women and Men. New York: Basic Books.

Fausto-Sterling A (2000) Sexing the Body. New York: Basic Books.

Fausto-Sterling A (2005) The bare bones of sex: Part 1-Sex and gender. Signs 30(2): 1491-1527.

Feinberg L (1998) Trans Liberation: Beyond Pink and Blue. Boston, MA: Beacon Press.

Fujimura JH (2006) Sex genes: A critical sociomaterial approach to the politics and molecular genetics of sex determination. Signs 32(1): 49-82.

Gatens M (1996) Imaginary Bodies. London: Routledge.

Gordon AR and Meyer IH (2008) Gender nonconformity as a target for prejudice, discrimination, and violence against LGBT individuals. Journal of LGBT Health Research 3(3): 55-71.

Greer G (1999) The Whole Women. London: Transworld Publishers.

Grosz E (1994) Volatile Bodies: Toward a Corporeal Feminism. Bloomington, IN: Indiana University Press.

Haas AP, Eliason M, Mays VM, et al. (2011) Suicide and suicide risk in lesbian, gay, bisexual, and transgender populations: Review and recommendations. Journal of Homosexuality 58(1): 10-51.

Haas AP, Rodgers PL and Herman JL (2014) Suicide attempts among transgender and non-conforming adults. Report for the Williams Institute. Available at: http://williamsinstitute.law.ucla.edu/wp-content/uploads/ AFSP-Williams-Suicide-Report-Final.pdf (accessed 30 March 2016).

Hausman BL (1995) Changing Sex: Transsexualism, Technology, and the Idea of Gender. Durham, NC: Duke University Press.

Heyes C (2003) Feminist solidarity after queer theory: The case of transgender. Signs 37(2): 1093-1120.

Hines S (2007) Transforming Gender: Transgender Practices of Identity, Intimacy and Care. Bristol: Polity Press. 
Hines S (2013) Gender Diversity, Recognition and Citizenship: Towards a Politics of Difference. Basingstoke: Palgrave Macmillan.

Jeffreys S (2003) Unpacking Queer Politics: A Lesbian Feminist Perspective. Cambridge: Polity Press.

Jeffreys S (2005) Beauty and Misogyny: Harmful Cultural Practices in the West. London: Routledge.

Jeffreys S (2008) They know it when they see it: The UK Gender Recognition Act 2004. British Journal of Politics \& International Relations 10: 328-345.

Jeffreys S (2014a) Gender Hurts: A Feminist Analysis of the Politics of Transgenderism. London: Routledge.

Jeffreys S (2014b) The politics of the toilet: A feminist response to the campaign to 'degender' a woman's space. Women's Studies International Forum 45: 42-51.

Koyama E (2003) The transfeminist manifesto. In: Stryker S and Piepmeier A (eds) Catching a Wave: Reclaiming Feminism for the 21st Century, Lebanon, N.H.: Northeastern University Press, pp. 244-259.

Landén M, Wålinder J, Hambert G, et al. (1998) Factors predictive of regret in sex reassignment. Acta Psychiatrica Scandinavica 97: 284-289.

Lawrence A (2003) Factors associated with satisfaction or regret following male-to-female sex reassignment surgery. Archives of Sexual Behavior 32(4): 299-315.

Liu RT and Mustanksi B (2012) Suicidal ideation and self-harm in lesbian, gay, bisexual and transgender youth. American Journal of Preventative Medicine 42: 221-228.

Lombardi EL, Wilchins RA, Priesing D, et al. (2001) Transgender experiences of violence and discrimination. Journal of Homosexuality 42(1): 89-101.

McNay L (2014) The Misguided search for the political. Cambridge: Polity.

McQueen P (2015a) Authenticity, intersubjectivity and the ethics of changing sex. Journal of Gender Studies. Epub ahead of print 3 August. DOI: 10.1080/09589236.2015.1063991.

McQueen P (2015b) Subjectivity, Gender and the Struggle for Recognition. Basingstoke: Palgrave Macmillan.

Mann R (2006) The treatment of transgender prisoners, not just an American problem - A comparative analysis of America, Australian and Canadian prison policies concerning the treatment of transgender prisoners and a 'universal' recommendation to improve treatment. Law and Sexuality: A Review of Lesbian, Gay, Bisexual and Transgender Legal Issues 15: 91-134.

Mason-Schrock D (1996) Transsexuals' narrative construction of the 'True Self'. Social Psychology Quarter 59(3): 176-192.

May K (2002) Becoming women: Transgendered identities, psychosexual therapy and the challenge of metamorphosis. Sexualities 5(4): 449-464.

Mikkola M (2011) Ontological commitments, sex and gender. In: Witt C (ed.) Feminist Metaphysics. Dordrecht: Springer.

Moi T (1999) What Is a Woman? Oxford: Oxford University Press.

Molotch H and Norén L (eds) (2010) Toilet: Public Restrooms and the Politics of Sharing. New York: NYU Press.

Monro S (2005) Gender Politics: Citizenship, Activism, and Sexual Diversity. Basingstoke: Palgrave Macmillan.

Moody C and Smith NG (2013) Suicide protective factors among trans adults. Archives of Sexual Behavior 42(5): 739-752.

Nagoshi JL, Stephan/ie B and Terrell HK (2012) Deconstructing the complex perceptions of gender roles, gender identity, and sexual orientation among transgender individuals. Feminism \& Psychology 22(4): 405-422.

Namaste V (2011) Sex Change, Social Change: Reflections on Identity, Institutions and Imperialism, 2nd edn. Toronto, ON, Canada: Women's Press.

National Center for Transgender Equality (NCTE) (2014) Transgender terminology. Available at: http://www. transequality.org/issues/resources/transgender-terminology (accessed 30 March 2016).

National Health Service (NHS) (2012) Suicide. Available at: http://www.nhs.uk/Conditions/Suicide/Pages/ Introduction.aspx (accessed 30 March 2016).

Olsson S and Möller A (2006) Regret after sex reassignment surgery in a male-to-female transsexual: A longterm follow up. Archives of Sexual Behavior 35(4): 501-506.

Overall C (2009) Sex/gender transitions and life-changing aspirations. In: Shrage L (ed.) You've Changed Sex Reassignment and Personal Identity. Oxford: Oxford University Press, pp. 11-27.

Overall C (2012) Trans persons, cisgender persons, and gender identities. In: Power N, Halwani R and Soble A (eds) Philosophy of Sex: Contemporary Readings, 6th edn, Lanham: Rowman \& Littlefield Publishers, pp. 251-267.

Pearce R (2014) No, I will not help Sundog make a documentary on trans 'regret'. Trans Activist Takes on World, 23 October. Available at: https://ransactivist.wordpress.com/2014/10/23/no-i-will-not-help-sundog-make-a-documentary-on-trans-regret/ (accessed 30 March 2016). 
Raymond J (1994 [1979]) The Transsexual Empire: The Making of the She-Male. London: Teachers College Press.

Riddell C (2006) Divided sisterhood: A critical review of Janice Raymond's The Transsexual Empire. In: Stryker S and Whittle S (eds) The Transgender Studies Reader. New York: Routledge, pp. 144-158.

Rosenblum D (2000) 'Trapped' in sing-sing: Transgendered prisoners caught in the gender binarism. Michigan Journal of Gender and Law 6: 499-571.

Rubin H (2003) Self-Made Man: Identity and Embodiment Amongst Transsexual Men. Nashville, TN: Vanderbilt University Press.

Sandland R (2005) Feminism and the Gender Recognition Act 2004. Feminist Legal Studies 13(1): $43-66$.

Schrock D, Reid L and Boyd EM (2005) Transsexuals' embodiment of womanhood. Gender \& Society 19(3): $317-335$.

Serano J (2007) Whipping Girl: A Transsexual Woman on Sexism and the Scapegoating of Femininity. Emeryville, CA: Seal Press.

Sharpe A (2012) Transgender marriage and the legal obligation to disclose gender history. The Modern Law Review 75(1): 33-53.

Shrage LJ (ed.). (2009) “You've changed”: Sex reassignment and personal identity. Oxford: Oxford University Press.

Smith YSL, van Goozen SHM and Cohen-Kettenis Peggy T (2001) Adolescents with gender identity disorder who were accepted or rejected for sex reassignment surgery: A prospective follow-up study. Journal of the American Academy of Child \& Adolescent Psychiatry 40(4): 472-481.

Smith YSL, van Goozen SHM, Kuiper AJ, et al. (2005) Sex reassignment: Outcomes and predictors of treatment for adolescent and adult transsexuals. Psychological Medicine 35: 89-99.

St James J (2015) 6 reasons why being called a cis person is not oppressive. Everyday Feminism, 15 January. Available at: http://everydayfeminism.com/2015/01/being-called-cis-is-not-oppressive (accessed 30 March 2016).

Stotzer RL (2009) Violence against transgender people: A review of United States data. Aggression and Violent Behavior 14(3): 170-179.

Stryker S (2013) Introduction. In: Stryker S and Aizura AZ (eds) The Transgender Studies Reader 2. New York: Routledge

Stryker S and Aizura AZ (eds) (2013) The Transgender Studies Reader 2. New York: Routledge.

Stryker S and Whittle S (eds) (2006) The Transgender Studies Reader. New York: Routledge.

Stryker S, Currah P and Moore LJ (2008) 'Introduction: Trans-, trans or transgender?'. WSQ: Women's Studies Quarterly 36(3\&4): 11-22.

Sweeney B (2004) Trans-ending women's rights: The politics of trans-inclusion in the age of gender. Women's Studies International Forum 27: 75-88.

UK Gender Recognition Act (2004) Available at: http://www.legislation.gov.uk/ukpga/2004/7/contents (accessed 30 March 2016).

Whittle S and Turner L (2007) 'Sex changes?' Paradigm shifts in 'sex' and 'gender' following the Gender Recognition Act? Sociological Research Online 12(1).

Whittle S, Turner L and Al-Alami M (2007) Engendered penalties: Transgender and transsexual experiences of inequality and discrimination. Report produced for The Equalities Review. Available at: http://www.pfc. org.uk/pdf/EngenderedPenalties.pdf (accessed 30 March 2016).

Whittle S, Turner L, Combs R, et al. (2008) Transgender eurostudy: Legal survey and focus on the transgender experience of health care. Available at: http://www.pfc.org.uk/pdf/eurostudy.pdf (accessed 30 March 2016). 